\title{
Expressão de metaloproteinases de matriz e de seus inibidores teciduais em carcinomas basocelulares
}

\author{
Expression of matrix metalloproteinasis and their tissue inhibitors in basal cell carcinoma
}

Rosy lara Maciel de Azambuja Ribeiro'; Paulo Cesar Borges Júnior2; ${ }^{2}$ Sérgio Vitorino Cardoso3; Ignez Candelori4; Foued Salmen Espíndola5; Geovanni Dantas Cassali6; Adriano Mota Loyola ${ }^{3}$

unitermos
Carcinoma basocelular
Metaloproteinase 2
Metaloproteinase 9
Inibidores teciduais de
metaloproteinases de
matriz 1
Inibidor tecidual de
metaloproteinase de
matriz 2
Imuno-histoquímica

\section{resumo}

Introdução: Aproximadamente $80 \%$ das neoplasias malignas de pele não-melanomas são carcinomas basocelulares (CBC). Apesar das raras metástases, esses tumores são localmente agressivos. As metaloproteinases de matriz (MMPs), especialmente as MMP-2 e 9, são importantes no processo de invasão. Em contrapartida, os inibidores teciduais das MMPs (TIMPs) têm como principal função a inibição dessas enzimas. Objetivo: Investigar a associação de variáveis clinicopatológicas de pacientes portadores de CBC com a expressão de MMP-2, MMP-9, TIMP-1 e TIMP-2. Material e métodos: Foram selecionados 31 casos de $C B C$, sendo então obtidos, retrospectivamente, os dados referentes a idade, sexo e tamanho da lesão. Cortes histológicos das lesões foram submetidos a reação imuno-histoquímica pela técnica estreptavidina-biotina-peroxidase para detecção dos antígenos de interesse. Índices de imunomarcação foram construídos e comparados com os dados previamente obtidos. Resultados: Observou-se correlação significativa entre idade e tamanho da lesão $(R=0,532 ; p=0,008)$. Não foram observadas correlações significativas entre as outras variáveis e a expressão imuno-histoquímica dos antígenos de interesse. Conclusão: A expressão das metaloproteinases e de seus inibidores teciduais não parece ser influenciada pelos parâmetros investigados. Estudos adicionais são necessários para melhor compreensão de sua associação com o comportamento biológico do CBC.

abstract

Introduction: Approximately $80 \%$ of non-melanoma skin neoplasias are basal cell carcinomas (BCC). Although metastasis is rare, $B B C$ carcinomas are locally aggressive tumors. Matrix metalloproteinases (MMPs), mainly MMP-2 and MMP-9, play an important role on the invasion process. On the other hand, tissue inhibitors of MMPs (TIMPs) have the main function of inhibiting these enzymes. Objective: To investigate the association of clinical-pathological variables of BCC patients with the expression of MMP-2 and MMP-9, TIMP-1 and TIMP-2. Methods: Thirty-one BCC cases were selected. Gender, age of the patients and size of the lesions were obtained retrospectively. Histological cuts of the lesions were exposed to immunohistochemistry reaction by use of the streptavidine-biotin peroxidase technique in order to detect antigens. Immunomarking parameters were established and compared with previous data. Results: A significant correlation between age and size of the lesion was observed $(R=0.532 ; p=0.008)$. No significant correlations between other variables and immunohistochemical expression of antigens were observed. Conclusion: The expression of MMPs and TIMPs does not seem to be influenced by the parameters investigated in this work. Additional studies should be made to better understand its association with the biological behavior of basal cell carcinomas. key words

Basal cell carcinoma

Matrix metalloproteinase 2

Matrix metalloproteinase 9

Tissue inhibitor

metalloproteinase 1

Tissue inhibitor

metalloproteinase 2

Immunohistochemistry

1. Mestra em Biologia Celular; doutora em Patologia pela Universidade Federal de Minas Cerais (UFMG).

2. Mestre em Bioquímica e Genética pela Universidade Federal de Uberlândia (UFU).

3. Doutor em Patologia; professor da área de Patologia da Faculdade de Odontologia da UFU.

4. Bióloga; especialista em imuno-histoquímica do Serviço de Anatomia Patológica do Hospital de Clínicas da UFU.

5. Doutor em Bioquímica; professor do Instituto de Genética e Bioquímica da UFU.

6. Doutor em Patologia; coordenador e professor do curso de pós-graduação em Patologia Geral da UFMG.

Trabalho realizado no Laboratório de Patologia Oral da Faculdade de Odontologia da UFU.

Apoio: Fundação de Amparo à Pesquisa do Estado de Minas Cerais (FAPEMIC) (CBS 881-01), Ministério da Ciência e Tecnologia e Conselho Nacional de Desenvolvimento Cientifico e Tecnológico (MCT/CNPq 465888-00-3).

Este trabalho é parte da tese de doutorado intitulada "Metaloproteinases 2 e 9: expressão, inibidores teciduais e inibição por extratos naturais no carcinoma de células basais e carcinoma espinocelular", apresentada no curso de pós-graduação em Patologia da Faculdade de Medicina da UFMG em 2007.

Esta investigação foi previamente submetida e aprovada pelo Comitê Institucional de Ética da UFU (Protocolo \# 12303). 


\section{Introdução}

Os carcinomas basocelulares ( $C B C$ ) constituem aproximadamente $80 \%$ das neoplasias malignas de pele, excluindo-se os melanomas, sendo sua origem fortemente associada à exposição excessiva à radiação ultravioleta. Apesar de raramente metastáticos, são localmente agressivos em decorrência de seu fenótipo notadamente invasivo ${ }^{(15)^{*}}$

As metaloproteinases de matriz (MMPs) constituem uma família de enzimas com atividade proteolítica relacionada geneticamente e cuja atividade é dependente de zinco. Diferem entre si estruturalmente e em sua habilidade em degradar um grupo particular de proteínas da matriz extracelular (MEC), sendo que, juntas, podem degradar todos os seus componentes protéicos. Essas enzimas têm sido associadas ao desenvolvimento de invasão e metástase neoplásicas. Em particular, a presença e/ou atividade de muitas das MMPs têm sido demonstradas em carcinomas, como o CBC e espinocelular ${ }^{(12,21,22,29,30)}$. As MMPs da classe das gelatinases, como as MMPs dos tipos 2 (MMP-2) e 9 (MMP-9), apresentam capacidade peculiar de degradar o colágeno IV que compõe a lâmina basal, sendo por isso provavelmente relevantes na aquisição do fenótipo invasivo das neoplasias malignas ${ }^{(13)}$.

Por outro lado, a expressão dos inibidores teciduais das MMPs (TIMPs) é observada durante a remodelação tecidual fisiológica, contribuindo para a manutenção do equilíbrio metabólico e estrutural da MEC. Alterações na homeostasia entre as MMPs e os TIMPs têm sido identificadas em doenças associadas à renovação não-controlada da MEC, como artrite, câncer, doenças cardiovasculares (DCVs), nefrites, desordens neurológicas e fibroses ${ }^{(19)}$. Os TIMPs dos tipos 1 (TIMP-1) e 2 (TIMP-2) representam membros bem caracterizados dessa família de inibidores e apresentam atividade inibitória contra as formas ativas de toda a família de $\operatorname{MMPs}^{(7,10)}$, embora a TIMP-1 forme preferencialmente complexo com a MMP-9, enquanto o TIMP-2 atua sobre a MMP-2. Ambos os inibidores têm atividade mitogênica em grande número de tipos celulares, enquanto que a superexpressão desses inibidores reduz o crescimento de células tumorais ${ }^{(8)}$. Finalmente, o TIMP-2 é considerado inibidor de invasão e metástase de células tumorais in vitro e in vivo ${ }^{(2,6)}$, e também da angiogênese associada a tumores ${ }^{(18)}$.

O objetivo deste trabalho foi investigar a associação de variáveis clinicopatológicas de pacientes portadores de CBC com a expressão das MMPs dos tipos 2 e 9 , bem como com as de TIMP dos tipos 1 e 2, e, ainda, avaliar possíveis associações desses marcadores nessas lesões.

\section{Material e métodos}

\section{Amostras}

Da casuística do Ambulatório de Pequenas Cirurgias do Hospital de Clínicas da Universidade Federal de Uberlândia (HC-UFU) foram coletados, prospectivamente, 30 casos de $\mathrm{CBC}$, sendo utilizados como critérios de inclusão, tamanho clínico da lesão $\geq$ a $0,5 \mathrm{~cm}$ e confirmação de diagnóstico em exame histopatológico. Para caracterização da amostra, foram registradas as informações de idade e sexo do paciente, além daquelas associadas ao aspecto clínico da lesão. Todos os pacientes apresentavam pele clara. As amostras foram obtidas por ressecção completa, sendo fixadas em formalina a $10 \%$ e, em seguida, embebidas em parafina. Para as análises histológicas, incluindo os ensaios imunohistoquímicos, foram realizados cortes teciduais de $3 \mu \mathrm{m}$ de espessura, os quais compreendiam toda a extensão das lesões. O diagnóstico histopatológico baseou-se nos critérios definidos pela Organização Mundial da Saúde (OMS), sendo também registrado o padrão histológico predominante $\mathrm{e}^{(14)}$.

\section{Imuno-histoquímica}

Os cortes histológicos foram desparafinados, hidratados e só então submetidos à recuperação antigênica com solução tampão de ácido etilenodiaminotetracético (EDTA) (1 mM, pH 8) em ambiente de microondas, perfazendo três ciclos de 5 minutos cada. Também foi realizado bloqueio da atividade de peroxidase e de biotina endógenas com água oxigenada (10 v) e solução comercial (Dako, Co Carpenteria, CA, EUA.), respectivamente. Em seguida, os cortes foram incubados com solução de avidina por um período de 20 minutos. As amostras foram incubadas com os anticorpos primários (clones Ab-4 anti-MMP-2, 1:800; Ab-3 anti MMP-9, 1:2.000; Ab-2 anti TIMP-1, 1:600; e Ab-2 anti-TIMP-2, 1:500; todos fabricados por Oncogene Inc.) por 18 horas, à temperatura ambiente. A amplificação da reação foi obtida com o sistema estreptoavidina-biotina-peroxidase (SABP), segundo as orientações do fabricante (Dako, EUA). A revelação da reação foi feita utilizando-se $3^{\prime}, 3^{\prime}$-tetraidrocloreto de diaminobenzidina (Sigma Chemical Co. MO). Os fragmentos teciduais foram então contracorados em hematoxilina de Harris $^{(4)}$. Como controle negativo, substituiu-se o anticorpo primário por solução de albumina de soro bovino (BSA) a $1 \%$ diluída em solução salina fosfatada (PBS) (pH 7,4); e como controles positivos foram usadas amostras de carcinoma ductal de mama previamente conhecidas como positivas para os antígenos pesquisados. 


\section{Avaliação da imunomarcação}

Para avaliação da imunomarcação foi observada a presença ou ausência de coloração acastanhada citoplasmática nas células neoplásicas, em fibroblastos próximos e naqueles distantes do tumor, independente de intensidade. Para cada amostra, 10 campos histológicos em grande aumento (objetiva original de $40 \mathrm{x}$ ) foram analisados, resultando em aproximadamente mil células. Finalmente, a proporção entre células marcadas e não-marcadas foi transformada em valores percentuais. Para cada um dos marcadores foram investigadas possíveis diferenças de sua expressão entre a epiderme e o carcinoma, tanto em termos de positividade quanto de intensidade (considerando-se padrão de forte intensidade a marcação da camada basal do epitélio adjacente à lesão). Além disso, foram investigadas possíveis relações entre a imunomarcação de MMP-9 e TIMP-1, e de MMP-2 e TIMP-2 no carcinoma. Finalmente, foi averiguada a possível associação entre a expressão dos marcadores nos fibroblastos e sua distribuição.

\section{Análise estatística}

Os testes de qui-quadrado $\left(\chi^{2}\right)$, tde Student e de Spearman foram utilizados para investigar a existência de associações, diferenças entre médias ou relações entre as variáveis de interesse, respectivamente, sempre com nível de significância fixado em 5\%, utilizando-se o software BioEstat ${ }^{(1)}$.

\section{Resultados}

Todos os pacientes apresentavam pele clara. Houve predomínio do sexo masculino (15 casos), com idade média global de 63,8 anos, variando entre 36 e 90 anos. As lesões localizavam-se predominantemente na face (15 casos), seguida por tronco (6 lesões) e membro superior ( 5 casos), sempre em superfícies que usualmente encontram-se expostas ao sol. O tamanho médio foi de $1,1 \mathrm{~cm}$, variando entre 0,5 e $3 \mathrm{~cm}$. Quando comparadas, observou-se relação estatisticamente significativa entre a idade dos pacientes e o tamanho das lesões (Figura 1). Após o diagnóstico histopatológico, 15 casos foram classificados como lesões de padrão sólido; 11 como esclerodermiforme; e quatro como micronodulares. Para análise estatística foram agrupadas de acordo com seu maior ou menor grau de invasibilidade, sendo 15 amostras de CBC sólido e 15 de padrão esclerodermiforme e micronodulares.

As expressões de MMP-2 e 9 e de TIMP-1 e 2 foram detectadas na epiderme não-neoplásica de todas as amos-

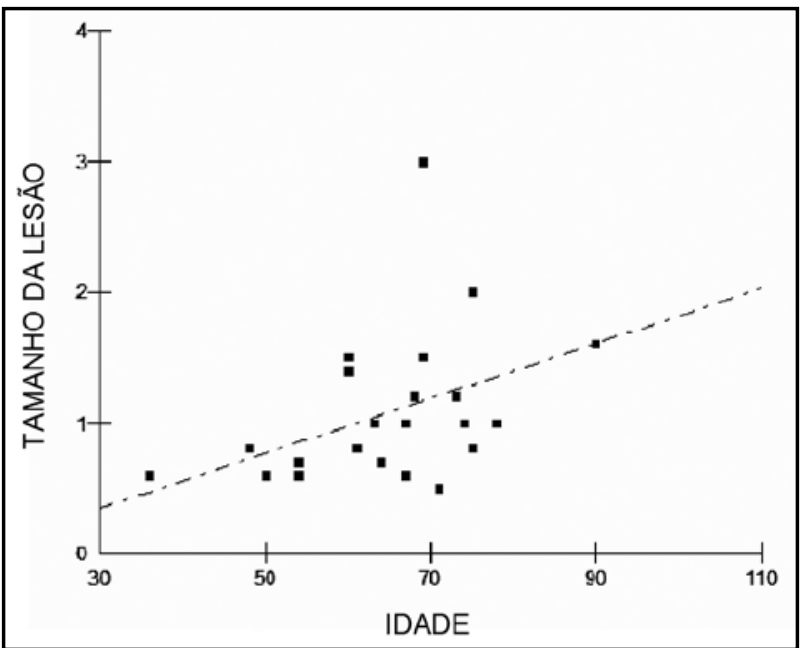

Figura 1 - Distribuição de casos de carcinoma basocelular de acordo com a idade dos pacientes e o tamanho da lesão $(R=0,532, p=0,008$, teste de Spearman)

tras, bem como em todos os epitélios neoplásicos, com exceção de três amostras em relação à MMP-2. Entretanto houve variação importante na intensidade de marcação desses antígenos (Figura 2). A ocorrência de marcação de forte intensidade foi significativamente mais freqüente na epiderme do que na neoplasia para todos os antígenos investigados, conforme mostrado na Tabela 1. Por outro lado, não houve diferença evidente na intensidade de marcação entre a periferia e o centro das ilhotas neoplásicas.

Quanto à intensidade de imunomarcação, de forma geral, a expressão dos TIMP foi mais tênue do que a das MMP. Em média, os índices de imunomarcação (número relativo de células marcadas) das enzimas estudadas foram de $43,7 \%( \pm 30,4 \%)$ para MMP-2, 78,8\% $( \pm 8,3 \%)$ para MMP-9, $82,5 \%( \pm 5,5 \%)$ para TIMP-1 e $71,2 \%( \pm 9 \%)$ para TIMP-2. Não houve correlação estatisticamente significativa

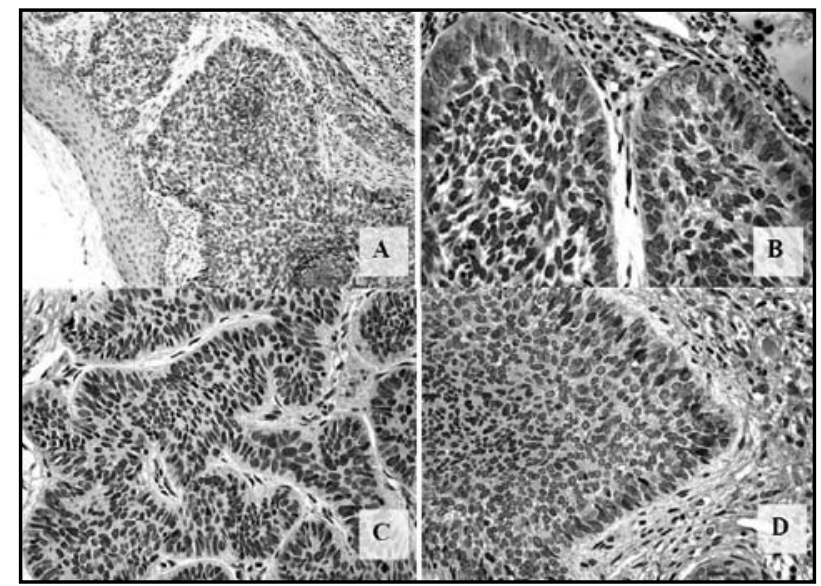

Figura 2 - Imunolocalização dos antígenos. A: MMP-2; B: MMP-9; C: TIMP-1; D: TIMP-2 em carcinoma basocelular. Notar imunolocalização de MMP-9 e TIMP-2 em fibroblastos vizinhos ao tumor (setas) (figura $4 A$, aumento de 200x; figuras $4 B, C$ e $D$, aumento de 600x) 


\section{Distribuição de carcinomas basocelulares e dos respectivos epitélios adjacentes, de acordo com a}

Tabela 1 intensidade de marcação de metaloproteinases de matriz e seus inibidores teciduais

\begin{tabular}{lcccccccc}
\hline & \multicolumn{3}{c}{ MMP-2* $^{*}$} & \multicolumn{2}{c}{ MMP-9* } & \multicolumn{3}{c}{ TIMP-1* TIMP-2* } \\
& + & ++ & + & ++ & + & ++ & + & ++ \\
Epiderme & 15 & 11 & 5 & 21 & 22 & 4 & 8 & 18 \\
CBC & 23 & 0 & 22 & 4 & 26 & 0 & 26 & 0 \\
\hline
\end{tabular}

${ }^{*} p<0,05$ (teste de qui-quadrado)

+ = marcação fraca; ++ = marcação forte.

entre os índices de expressão de TIMP-1 e MMP-9 e de TIMP-2 e MMP-2. Quando os índices médios de imunomarcação desses antígenos foram comparados segundo o tipo histológico predominante (sólido vs. esclerodermiforme e micronodulares), só foi detectada diferença estatisticamente significativa para TIMP-1 ( $p=0,04$, teste de Mann Whitney) (Figura 3). A idade dos pacientes ou o tamanho das lesões também não apresentaram nenhuma relação estatisticamente relevante com os marcadores estudados, embora uma relação direta entre tamanho e expressão de TIMP-1 tenha se aproximado do limite de significância $(R=$ $0,38 ; p=0,06)$.

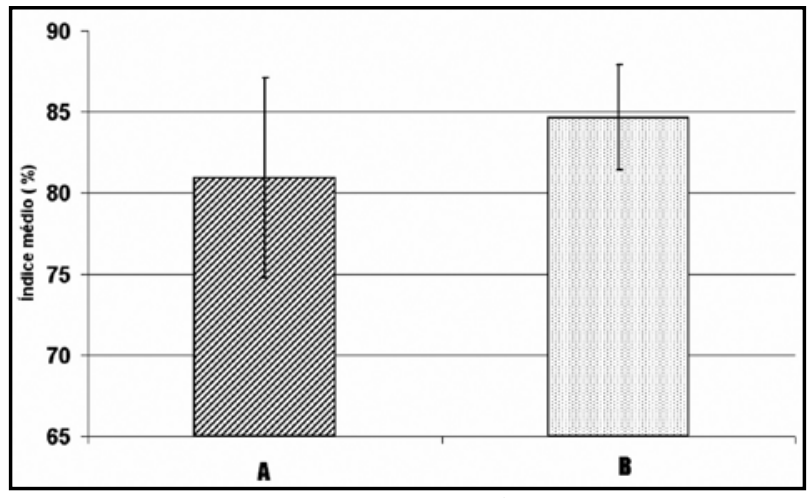

Figura 3 - A: Carcinomas basocelulares de padrão sólido; B: carcinomas basocelulares de padrão esclerodermiformes e micronodulares. Observou-se diferença estatística para TIMP-1 $(\mathrm{p}=0,04)$ entre $A$ e $B$
Para todos os marcadores, os fibroblastos adjacentes às células neoplásicas apresentaram maior freqüência de marcação disseminada do que aqueles encontrados em locais mais distantes. Entretanto, essa associação foi estatisticamente significativa apenas para a MMP-9 e para as TIMPs, conforme apresentado na Tabela 2.

\section{Discussão}

Os processos de crescimento, invasão e metástase tumorais envolvem diversos fenômenos biológicos complexos: proliferação celular, digestão proteolítica e migração através dos componentes da matriz celular. As metaloproteinases de matriz são consideradas moléculas fundamentais em várias etapas da progressão tumoral, como crescimento, invasão e metástase, sendo o aumento de sua expressão geralmente associado a pior prognóstico ${ }^{(20)}$. O desequilíbrio entre MMPs e seus inibidores teciduais (TIMPs) parece ser essencial para a degradação da MEC. Esse evento, mais freqüente no microambiente das neoplasias malignas, tem sido implicado ao seu potencial de invasibilidade e agressividade ${ }^{(28)}$. Apesar dos $\mathrm{CBCs}$ raramente apresentarem comportamento agressivo, são lesões em que há crescimento tumoral e invasibilidade evidentes, e inúmeras vezes preocupantes. No presente estudo foi investigada a expressão das enzimas MMP-2, MMP-9, TIMP-1 e TIMP-2 em CBCs e os resultados

Tabela 2

Distribuição de fibroblastos em carcinomas basocelulares, relacionando o padrão de imunomarcaçãa de metaloproteinases de matriz e seus inibidores teciduais com a localização

\begin{tabular}{lcccccccc}
\hline & \multicolumn{3}{c}{ MMP-2 } & \multicolumn{2}{c}{ TIMP-1* } & \multicolumn{3}{c}{ TIMP-2* } \\
& D & O/A & D & O/A & D & O/A & D & O/A \\
Adjacentes & 11 & 20 & 27 & 4 & 10 & 21 & 13 & 18 \\
Distantes & 5 & 25 & 11 & 19 & 2 & 28 & 4 & 26 \\
\hline
\end{tabular}

${ }^{*} \mathrm{p}<0,05$ (teste de qui-quadrado).

$D=$ marcação disseminada; $O / A=$ marcação ocasional ou ausente.

Obs.: um caso não apresentava tecido conjuntivo suficiente para esta análise. 
foram discutidos à luz das lesões com diferentes padrões de comportamento biológico.

Na epiderme não-neoplásica, a expressão de MMP e TIMP foi freqüentemente identificada nos queratinócitos das camadas basais. Esses achados têm sido descritos por outros autores em epiderme de pele não-associada à neoplasia, fato que tem sido interpretado como expressão antigênica constitutiva ${ }^{(17,23)}$. Assim, e considerando-se que o CBC apresenta caracteristicamente diferenciação semelhante às células localizadas na camada basal do epitélio, optamos por enfatizar a avaliação dessas enzimas no parênquima neoplásico, diferentemente da maioria dos estudos anteriores, que optaram por investigar exclusivamente a sua expressão em fibroblastos estromais.

Nossos resultados evidenciaram que as metaloproteinases e seus inibidores teciduais foram expressos de forma heterogênea no parênquima neoplásico. Ademais, a imunomarcação de forte intensidade dos antígenos de interesse foi mais freqüentemente observada na epiderme adjacente do que propriamente nas neoplasias.

O fato de serem usualmente diagnosticadas em estágios clínicos precoces tem contribuído para reforçar o conceito de baixa agressividade associado a essas lesões. Não obstante seu reconhecido fenótipo pouco agressivo, seu fenótipo de invasibilidade potencial tem sido atestado, especialmente nos casos de longo tempo de evolução em que as lesões se apresentam deformantes devido ao grau de destruição que produzem. Nossos achados vão ao encontro da possibilidade da participação das MMPs e dos TIMPs na modulação de um comportamento invasivo próprio aos CBCs. De fato, estudos prévios têm observado intensa atividade colagenolítica em $\mathrm{CBCs}^{(3)}$. É possível que esse comportamento particular de invasibilidade dos $C B C$ s possa ser explicado pela baixa expressão das metaloproteinases e seus inibidores, que, regulados por mecanismos particulares ainda pouco desconhecidos, explicariam a expressão de sua invasibilidade a longo prazo.

Nesse sentido, a ausência de relação significativa entre TIMP-1 e MMP-9, bem como entre TIMP-2 e MMP-2, parece também indicar que mecanismos subjacentes e ainda ignorados possam influenciar a expressão das próprias metaloproteinases. Sabe-se, por exemplo, que citocinas e outros fatores presentes no microambiente tumoral podem influenciar a síntese e a atividade biológica dessas enzimas ${ }^{(5)}$. Todavia o significado desses achados na progressão dos CBCs ainda carece de confirmação.

Um aspecto que merece discussão é a diferença de expressão de TIMP-1 entre os tumores de diferentes potenciais de invasibilidade. Nossos resultados mostraram maiores índices de expressão nas neoplasias esclerodermiformes e micronodulares, estatisticamente diferentes daqueles avaliados nas lesões sólidas. Achados referentes à expressão de MMPs e seus inibidores têm sido contraditórios para CBCs cutâneos. Adicionalmente, os estudos até então realizados não se preocuparam em avaliar expressão diferenciada para os diferentes tipos de $\mathrm{CBCs}$, o que limita nossa discussão. Entretanto, estudos realizados com carcinomas mamários têm identificado que a expressão de TIMP (tecidual e sérica) associa-se ao fenótipo de maior agressividade, constituindose indicador de pior prognóstico(20,25-27).

A propósito, diversos trabalhos indicam que a TIMP-1 é uma proteína multifuncional que, além de seu efeito inibidor sobre as MMPs, possui funções distintas, entre elas a de estimular o crescimento tumoral ${ }^{(22)}$. Esse estímulo parece ser independente da atividade inibitória de MMPs, o que explicaria, em parte, os resultados da alta expressão nos cânceres de comportamento mais agressivo ${ }^{(16,24,11)}$. Dessa forma, os achados descritos neste trabalho, a priori, poderiam ser examinados à luz de duas situações distintas, porém relacionadas: a) a expressão mais elevada de TIMP seria de natureza reacional, vinculada a um processo de modulação das MMPs, o que justificaria seu comportamento mais indolente; b) a expressão de TIMPs estaria dissociada da expressão de MMPs, vinculando-se a um padrão de alteração genética próprio da progressão das lesões esclerodermiformes e micronodulares, em que sua concentração poderia favorecer um efeito proliferativo e não-inibitório do crescimento neoplásico. Essas hipóteses carecem obviamente de melhor apreciação por estudos com metodologia apropriada.

O presente trabalho também mostrou não haver relação estatisticamente significativa entre os índices de expressão no epitélio tumoral de TIMP-1 e MMP-9 e de TIMP-2 e MMP-2, ou seja, a diminuição da freqüência de ocorrência de marcação de forte intensidade de MMPs observada entre a epiderme adjacente e o tecido neoplásico não pôde ser associada ao aumento do número de células positivas para as TIMPs neste estudo. Estudos com carcinomas epidermóides de língua consideram positivos somente os casos em que a intensidade de coloração do tumor é maior do que a encontrada no epitélio normal(9). Nossos resultados foram observados considerando positivos todos os casos com imunomarcação, independente da intensidade em relação ao epitélio normal, sendo que todas as amostras estudadas apresentaram positividade para todos os marcadores investigados. 
Por outro lado, os fibroblastos mais próximos ao tecido neoplásico epitelial apresentaram mais freqüentemente imunomarcação disseminada quando em comparação com as células mais distantes (Figura 2D). Essa observação parece indicar que as células neoplásicas seriam capazes de influenciar a expressão gênica das células parenquimatosas, alterando especificamente a atividade metabólica relacionada à manutenção da MEC. De fato, outros estudos já demonstraram tal influência, inferindo-se daí que parte significativa da degradação dos componentes da matriz seja devida a esse mecanismo.

Em conclusão, nossos resultados demonstraram que, ainda que tenha sido identificada diminuição evidente na ocorrência de forte marcação entre a epiderme e o epitélio neoplásico, não houve relação entre os marcadores utilizados (entre si e com os dados clínicos coletados), bem como com o tipo histológico das lesões. Portanto estudos adicionais são necessários para melhor compreensão da associação dessas enzimas ao comportamento biológico do CBC.

\section{Referências}

1. AIRES, M. et al. BioEstat 4.0: aplicações estatísticas nas áreas das ciências biológicas e médicas. Ed. Sociedade Civil Mamirauá/MCT/Imprensa Oficial do Estado do Pará. Belém. 2005. 323p.

2. ALBINI, A. et al. Tumor cell invasion inhibited by TIMP-2. J Natl Cancer Inst, v. 5, n. 83, p. 775-9, 1991.

3. BAUER, E. A. et al. Quantitation and immunochemical localization of human skin collagenase in basal cell carcinoma. J. Invest. Dermatol, v. 69, n. 4, p. 363-7, 1977.

4. BEHMER, A. O. et al. Manual de técnicas para histologia normal e patológica. São Paulo: Edit. USP, 1976.

5. CIRCOLO, A. et al. Differential regulation of the expression of proteinases/antiproteinases in fibroblasts. Effects of interleukin-1 and platelet-derived growth factor. J Biol Chem, v. 266, n. 19, p.12283-8, 1991.

6. DECLERCK, Y. A. Inhibition of tumor invasion of smooth muscle cell layers by recombinant human metalloproteinase inhibitor. Cancer Res, v. 51, n. 8, p. 2151-7, 1991.

7. FOLGUERAS, A. R. Matrix metalloproteinases in cancer: from new functions to improved inhibition strategies. Int J Dev Biol, v. 48, p. 411-24, 2004.

8. GOMEZ, D. E. Tissue inhibitors of metalloproteinases: structure, regulation and biological functions. Eur J Cell Biol, v. 74, n. 2, p. 111-22, 1997.

9. GUTTMAN, D. Expression of MMP-9, TIMP-1, CD-34 and factor-8 as prognostic markers for squamous cell carcinoma of the tongue. Oral Oncol, v. 40, n. 8, p. 798-803, 2004.

10. HOWARD, E. W. et al. Preferential inhibition of 72- and 92$\mathrm{kDa}$ gelatinases by tissue inhibitor of metalloproteinases2. J Biol Chem, v. 266, n. 20, p. 13070-5, 1991.

11. JOO, Y. E. et al. Expression of tissue inhibitors of metalloproteinases (TIMPs) in gastric cancer. Dig Dis Sci, v. 45, n. 1, p. 114-21, 2000.

12. KARELINA, T. V. Localization of 92-kDa type IV collagenase in human skin tumors: comparison with normal human fetal and adult skin. J Invest Dermatol, v. 100, n. 2, p. 159-65, 1993.

13. KERKELÄ, E.; SAARIALHO-KERE, U. Matrix metalloproteinases in tumor progression: focus on basal and squamous cell skin cancer. Exp Dermatol, v. 12, n. 2, p. 109-25, 2003.

14. KOSSARD, S. et al. Basal cell carcinoma. In: LEBOIT, P. et al. (eds.). World Health Organization Classification of tumours. Pathology and genetics of Skin Tumors. Lyon: IARC Press, 2006. p. 13-9.

15. MACKIE, R. M. Long-term health risk to the skin of ultraviolet radiation. Prog Biophys Mol Biol, v. 92, n. 1, p. 92-6, 2006.

16. MÃ̃̃ATA, M. et al. Matrix metalloproteinase-2 (MMP-2) and -9 (MMP-9) and their tissue inhibitors (TIMP-1 and TIMP-2) in differential diagnosis between low malignant potential (LMP) and malignant ovarian tumours. Anticancer Res, v. 27, n. 4C, p. 2753-8, 2007.

17. MONHIAN, N. Matrix metalloproteinase expression in normal skin associated with basal cell carcinoma and in distal skin from the same patients. Arch Facial Plast Surg, v. 7, n. 4, p. 238-43, 2005.

18. MURPHY, A. N. Tissue inhibitor of metalloproteinases2 inhibits bFGF-induced human microvascular endothelial cell proliferation. J Cell Physiol, v. 157, n. 2, p. 351-8, 1993.

19. Nagase, H.; Woessner, J. F. Jr. Matrix metalloproteinases. J Biol Chem, v. 274, n. 31, p. 21491-4, 1999.

20. NAKOPOULOU, L. Enhanced mRNA expression of tissue inhibitor of metalloproteinase-1 (TIMP-1) in breast carcinomas is correlated with adverse prognosis. J Pathol, v. 197, n. 3, p. 307-13, 2002.

21. POULSOM, R. Expression of gelatinase A and TIMP-2 mRNAs in desmoplastic fibroblasts in both mammary carcinomas and basal cell carcinomas of the skin. $J$ Clin Pathol, v. 46, n. 5, p. 429-36, 1993.

22. PYKE, C. Localization of messenger RNA for Mr 72,000 and 92,000 type IV collagenases in human skin cancers by in situ hybridization. Cancer Res, v. 52, n. 5, p. 1336-41, 1992.

23. RAITIO, A. Levels of matrix metalloproteinase-2, -9 and -8 in the skin, serum and saliva of smokers and nonsmokers. Arch Dermatol Res, v. 297, n. 6, p. 242-8, 2005.

24 RAUVALA, M.; PUISTOLA, U.; TURPEENNIEMI-HUJANEN, 
T. Gelatinases and their tissue inhibitors in ovarian tumors; TIMP-1 is a predictive as well as a prognostic factor. Gynecol Oncol Dec, v. 99, n. 3, p. 656-63, 2005.

25. REE, A. H. et al. High levels of messenger RNAs for tissue inhibitors of metalloproteinases (TIMP-1 and TIMP2) in primary breast carcinomas are associated with development of distant metastases. Clin Cancer Res, v. 3, n. 9, p.1623-8, 1997.

26. SCHROHL, A. S. Tumor tissue concentrations of the proteinase inhibitors tissue inhibitor of metalloproteinases-1 (TIMP-1) and plasminogen activator inhibitor type 1 (PAI-1) are complementary in determining prognosis in primary breast cancer. Mol Cell Proteomics, v. 2, n. 3, p. 164-72, 2003.
27. SCHROHL, A-S. Tumor tissue levels of tissue inhibitor of metalloproteinase-1 as a prognostic marker in primary breast cancer. Clin Cancer Res, v. 10, p. 2289-98, 2004.

28. STAMENKOVIC, I. Matrix metalloproteinases in tumor invasion and metastasis. Semin Cancer Biol, v. 10, n. 6, p. 415-33, 2000.

29. WAGNER, N. S. Differential expression of tissue inhibitor of metalloproteinases- 2 by cutaneous squamous and basal cell carcinomas. J Invest Dermatol, v. 106, p. 321-6, 1996.

30. Yucel, T. Matrix metalloproteinase expression in basal cell carcinoma: relationship between enzyme profile and collagen fragmentation pattern. Exp Mol Pathol, v. 79, n. 2, p. 151-60, 2005. 